\title{
Plant Location Selection for Food Production by Considering the Regional and Seasonal Supply Vulnerability of Raw Materials
}

\author{
Jin Woo Park $\mathbb{D}^{1},{ }^{1}$ Ha Young Oh ${ }^{D},{ }^{1}$ Duck Young Kim $\left(\mathbb{D},{ }^{1}\right.$ and Yong Ju Cho ${ }^{2}$ \\ ${ }^{1}$ Department of System Design and Control Engineering, Ulsan National Institute of Science and Technology, \\ Ulsan, 44919, Republic of Korea \\ ${ }^{2}$ Korea Institute of Industrial Technology, Cheonan, 31056, Republic of Korea \\ Correspondence should be addressed to Duck Young Kim; dykim@unist.ac.kr
}

Received 16 October 2018; Accepted 19 November 2018; Published 10 December 2018

Academic Editor: Thomas Hanne

Copyright (C) 2018 Jin Woo Park et al. This is an open access article distributed under the Creative Commons Attribution License, which permits unrestricted use, distribution, and reproduction in any medium, provided the original work is properly cited.

\begin{abstract}
A production capacity analysis considering market demand and raw materials is very important to design a new plant. However, in the food processing industry, the supply uncertainty of raw materials is very high, depending on the production site and the harvest season, and further, it is not straightforward to analyze too complex food production systems by using an analytical optimization model. For these reasons, this study presents a simulation-based decision support model to select the right location for a new food processing plant. We first define three supply vulnerability factors from the standpoint of regional as well as seasonal instability and present an assessment method for supply vulnerability based on fuzzy quantification. The evaluated vulnerability scores are then converted into raw material supply variations for food production simulation to predict the quarterly production volume of a new food processing plant. The proposed selection procedure is illustrated using a case study of semiprocessed kimchi production. The best plant location is proposed where we can reduce and mitigate risks when supplying raw material, thereby producing a target production volume steadily.
\end{abstract}

\section{Introduction}

Plant design involves major business considerations, including market demand, plant location, nature of the product, construction and operation costs, production capacity, government policy, climate, and potential competitors [1-5]. In particular, strategic decisions for plant location and production capacity are the key for business success in the food processing industry since these decisions in the early plant design phase predetermine most of the plant operation cost.

The plant location decision has often been formulated as a cost optimization problem by converting the associated decision attributes into monetary values. This cost optimization model usually involves decision making regarding the following attributes: market demand, production and storage capacity, production cost, and supply reliability [6-12]. This optimization model has been extended by incorporating uncertainty-variation of population, changeable market trends, and unpredictable demand-into the decision-making process [13].
A food plant is usually located close to either customers or raw material growing regions, depending on the nature of the product. In addition, the daily production volume must be carefully planned to avoid shouldering the extra cost of excessive production $[14,15]$. Thus, the plant location decision can be considered from a supply reliability standpoint. Although the stable supply of raw materials has often been assumed in previous production capacity analysis, this ideal assumption does not always hold in food production. In other words, there are many sources of uncertainty, including quality deterioration, seasonal variation of production quantity, unstable climate, and natural disasters [16, 17]. In general, a decision model for plant location selection requires a precise estimation of the production capacity of each prospective location for which several simulation-based methods have been proposed in the literature; it is not straightforward to analyze too complex food production systems by using an analytical optimization model [18-21].

This study presents a simulation-based decision support model to select the right location for a new food processing 
plant. In particular, the simulation model of food production accounts for the supply uncertainty of raw materials depending on the production site and the harvest season in the food processing industry. However, it is very difficult to make precise decisions in complex and uncertain problems if the acquired data is imprecise or insufficient $[22,23]$. In order to overcome this difficulty, we define the supply vulnerability factors of raw materials such as production quantity in a food-growing region, market demand, and distance. All these factors are assessed and aggregated to determine the degree of vulnerability in the form of fuzzy rules. The evaluated vulnerability scores are then converted into raw material supply variations for food production simulation to predict the quarterly production volume of a new food processing plant. For production simulation, we conduct the probability distribution analysis to estimate the supply failure rate and the duration of failure. Finally, we simulate the daily food production volume in all prospective plant locations and select a location that guarantees the production of the target quantity, despite the unstable supply of raw materials. The simulation results, in fact, help decision stakeholders make a relative rank order, even without sufficient supply failure data, and eventually, the final selection is made based on the relative ranking. The proposed selection procedure is illustrated using a case study of semiprocessed kimchi production.

\section{Related Works}

The plant location selection problem is normally considered as a part of supply chain network design. To minimize the total cost as well as determine an optimal flow path for a product, previous studies have focused on demand variations, because the quality of decisions can easily vary due to supply and demand uncertainty, ambiguous information, and various social problems in the global business network $[9,24,25]$. It is likely that a stochastic model, rather than a deterministic approach, can be used to express demand uncertainty. Wang et al. [7] used a stochastic programming model that implies uncertain demand to find a location that maximizes business profits. Amin and Zhang [9] also considered the demand and return uncertainty of a product through the stochastic programming model. Moreover, they included environmental factors, such as the use of eco-friendly materials and clean technology, and used the weighted sum method as well as the $\varepsilon$-constraint method for multiobject optimization. Gülpınar et al. [26] proposed two types of demand distributions (i.e., normal distribution and context intended distribution) regarding facility location in a dynamic environment. Besides that, Wagner and Neshat [27] applied the quantification method to assess supply chain vulnerability. Based on the graph theory, their method of quantifying vulnerability can be dynamically adapted, even if the supply chain is frequently redesigned. In short, the quantification of the supply vulnerability of a food production system must consider production variables such as the properties of food raw materials, changes in production quantities during different seasons, and dynamic market changes [28].
In addition to fuzzy-based research, several optimization models for supporting decision making have been proposed. Jouzdani et al. [29] proposed a fuzzy model that used a triangular membership function to deal with demand uncertainty in a dairy plant. They considered traffic congestion as an essential factor for selecting the location because the dairy industry is very sensitive to demand variations and the localization of the food industry usually affects supply chain costs. Çebi and Otay [1] proposed a fuzzy-based location selection model for a cement plant by considering various qualitative factors such as availability of resources, strategic factors, government policies, and environmental factors. Mirhadi Fard et al. [6] considered environmental, social, and economic impacts as qualitative decision criteria to choose a sustainable plant location. Moreover, they took into account continuously changing geographic information in the service region and specified spatial characteristics such as accessibility of raw materials and proximity to the market. Rezaei and Zarandi [30] proposed a fuzzy model for dealing with dynamic environments at the initial location of a plant. They also developed a simulation model to recognize any changes in the service region. Moreover, applying seasonal parameters is one solution for ensuring the reliability of a decision model for plant location. Ozgen and Gulsun [31] used triangular possibility distribution (a fundamental part of the possibility theory) to deal with supply and demand uncertainty, along with climate as a seasonal parameter. More specifically, they combined the possibility distribution with the fuzzy analytic hierarchy process (AHP) method to handle both the quantitative and qualitative factors in the decision-making process. However, it is difficult to decide the shape of a membership function for representing the aggregation of data set in fuzzy-based decision-making model; hence the specialist interviews are usually required. Fuzzy TOPSIS approaches have been proposed for selecting a plant location by linguistically evaluating the following criteria: availability of skilled workers, expansion possibility, availability of acquirement material, and investment cost [32]. Aqlan and Lam [33] proposed a fuzzy-based method for supply chain risk assessment and quantified aggregate information, such as expert knowledge, historical data, and supply chain structure, to identify potential risks. Deb and Bhattacharyya [18] proposed a distinct decision support system that uses a multifactor fuzzy inference system for facility layout planning. Dweiri and Meier [19] also applied fuzzy decision making to facility layout planning and used the distance between departments and their relationships for scoring the planned layout.

Askin et al. [34] proposed a genetic algorithm-based method for warehouse location selection and determined the best capacity design for the selected warehouse. They also set the objective function to minimize costs due to demand variations, after which the optimal economic order quantity was derived to continuously adapt to the volatile inventory levels. However, metaheuristic optimization methods such as genetic algorithm-based optimization sometimes require a lot of time to find the optimal solution. Novaes et al. [35] used the Voronoi diagram, useful for conducting spatial analysis, to divide an urban region into service districts. 
It is important to note that the process parameters of a production system, which determine the productivity of a plant, help decision makers improve the quality of their decision regarding location selection. In this regard, Silva and De La Figuera [36] proposed the integrated approach to find the best plant location using both a stochastic model of a manufacturing system and a deterministic location model. Their study examines the arrival time of customers as well as the processing time and capacity planning of the manufacturing system. Gebennini et al. [37] considered production lead time and delayed quantities of a product to determine demand variations and supply uncertainty. Consequently, in order to make more accurate decisions, various uncertain environmental factors need to be assessed by the appropriate quantification methods.

Vulnerability assessments usually underpin supply chain management due to the quantification of uncertain disturbances for mitigating risk [38,39]. Albino et al. [40] proposed a quantification method to measure the vulnerability of a production system within a multisupplier network and evaluate critical aspects using two factors, i.e., process uncertainty and product mix variability. Petrovic et al. [41] developed the supply chain simulator to analyze the dynamic behaviour of a serial supply chain in an uncertain environment. For this purpose, they proposed discrete fuzzy sets for modeling uncertain situations in customer demand and external supply to determine the negative effects. Vorst et al. [42] identified sources of uncertainty (e.g., decision process time, order lead time, and order sales period) to improve supply chain performance and validated the trends predicted by the simulation model. Vlajic et al. [28] proposed an integrated framework for guiding food companies, in which supply chain robustness was defined to identify various disturbances through the classified sources of supply chain vulnerability, including external and internal sources that are either controllable or uncontrollable. However, their research mainly focused on internal sources of vulnerability to design robust food supply chains.

In the food industry, since fresh products have a limited shelf life, it is particularly difficult to have many goods in stock at all times [33]. Thus, supply chain management and production planning for fresh products should be carefully conducted when the inventory levels are low [43, 44]. It is important to note that the supply failure of raw materials caused by inaccurate demand predictions and tardiness of finished (or semifinished) products are major factors that trigger vulnerability, which can ultimately disrupt production. Furthermore, as the food industry becomes more globalized, the importance of optimal supply chain management has increasingly been emphasised [45].

Previous studies have seldom considered an integrated approach for selecting the best plant location using both stochastic simulation and vulnerability quantification, even though many studies have addressed simulation-based optimal layout design. Further, most of the studies considered the supply of raw materials to be relatively stable. Therefore, this study proposes an integrated approach that combines a supply vulnerability analysis and statistical simulation to deal with various uncertain factors (e.g., unstable supply of food raw materials) during plant location selection.

\section{Simulation-Based Plant Location Selection}

\subsection{The Plant Location Problem}

3.1.1. Cabbage Production Quantities and Supply Failure Data. The problem in hand is to select the best location for a new semiprocessed kimchi plant by using the imprecise information provided by our research partner, World Institute of Kimchi. This information includes food production conditions, plant operation data, and average supply failure data as shown in Figure 1.

The proposed model for plant location selection is aimed at supporting decision makers when they have difficulty in estimating a suitable distribution form related to supply failures for simulation modeling due to the lack of information. In other words, we could not estimate a probability density function using the conventional distribution fitting because there was no detailed supplier failure information such as date and duration of each failure in a specific region. We approximated distribution forms by a fuzzy supply vulnerability analysis based on food production conditions and average supply failure data as shown in Figure 1. It is recommended for decision makers to choose normal, exponential, and gamma distributions that have been widely used for failure occurrence modeling in the literature.

Figure 2 illustrates the food production conditions for the eight prospective locations and the four seasons which include the production quantities in locations, the area of the production region, the demand for food raw materials, the number of customers, and the annual mean temperature. These conditions play critical roles in determining the seasonal production quantities.

It is assumed that the delivery distance for raw materials is related to the area of the production and, hence, the delivery time in a relatively large area is longer than that in a small area. For the sake of simplicity, other decisive factors, such as delivery cost per mile, taxation, plant construction, operation cost, and local government policies, are assumed to be the same for all locations.

3.1.2. Plant Location Selection Procedure. This section presents the basic ideas of plant location selection considering the unstable supply of food raw materials. In the food industry, unexpected conditions, such as natural disasters, abnormal climate, or the abandonment of cultivation, sometimes lead to shortfalls in the supply of raw materials. In this case, a food manufacturer should search for alternative sources for food raw materials in other regions. We take this supply shortage situation into account for a supply vulnerability factor, that is, the possibility of replacing raw material feedstock using alternative sources. It can be said that if the possibility is small, the supply vulnerability is high. The plant location selection procedure is illustrated by a case study of semiprocessed kimchi production. The case study was chosen upon the request of our research partner, World 


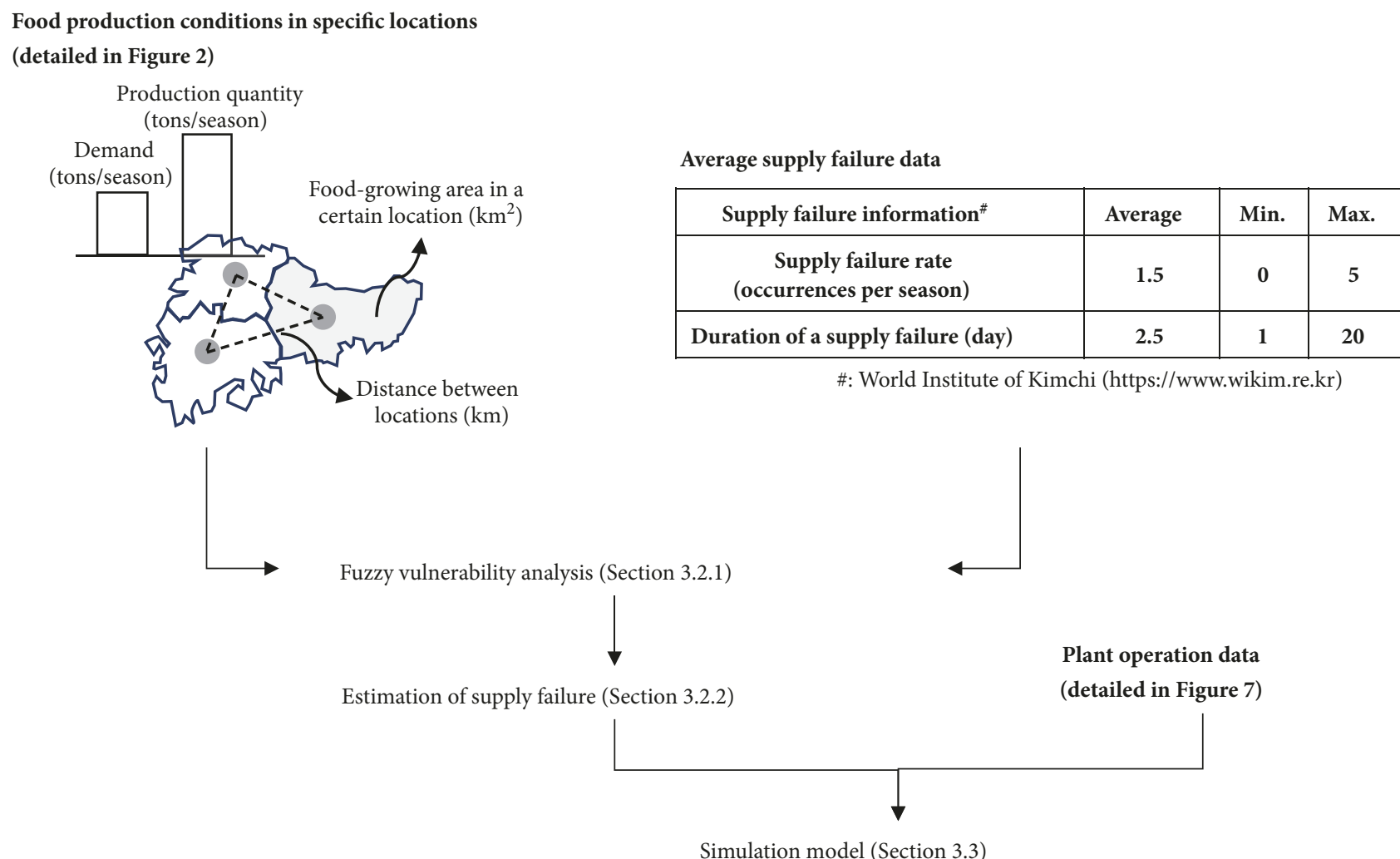

FIgURE 1: The given information for plant location selection.

Institute of Kimchi, who are aiming to construct a new kimchi processing plant in a suitable location.

Kimchi is a traditional Korean side dish made by combining cabbage and other fermented vegetables in a salted brine. Recently, there has been a strong customer demand for semiprocessed kimchi and, hence, many food manufacturers have focused their attention on building new semiprocessed kimchi plants that can automatically produce salted cabbage on a large scale. The main raw materials for this process include a considerable amount of cabbage, salt, and water, of which the stable supply of cabbage is the most important, irrespective of seasonal and regional variations.

As illustrated in Figure 3, the plant location selection procedure involves the supply vulnerability analysis by estimating supply failure rates and failure durations and stochastic simulation as follows:

Step 1 (vulnerability analysis). Quantify the fuzzy supply vulnerability from the standpoint of regional and seasonal instability in the supply of raw materials.

Step 2 (simulation modeling).

(i) Convert the quantified supply vulnerability scores (the instability level of raw material supply in a specific region) into raw material supply variations.

(ii) Estimate supply failure rates (the number of supply failure occurrences per season) from the supply vulnerability scores. (iii) Adjust the probability density functions for the supply failure durations (inter-supply failure time).

(iv) Specify production process parameters (e.g., malfunction rate, processing time).

Step 3 (simulation-based location selection).

(i) Adjust the daily utilization of a production system.

(ii) Calculate a target production volume and an estimated production volume using the adjusted daily utilization.

(iii) Determine the best plant location.

Table 1 summarizes the variables used in the production volume estimation for the proposed method.

\subsection{Supply Failure Estimation by a Fuzzy Vulnerability Analysis}

3.2.1. Fuzzy Vulnerability Analysis. For supply failure estimation, the supply vulnerability of food raw materials is incorporated into the simulation model in which three main vulnerability factors are involved: raw material availability, production efficiency of raw material, and possibility of replacing raw material feedstock using alternative sources.

(1) Raw material availability assesses whether the amount of raw materials meets the market demand, including the current consumption by competitors in a prospective plant location. It can be 


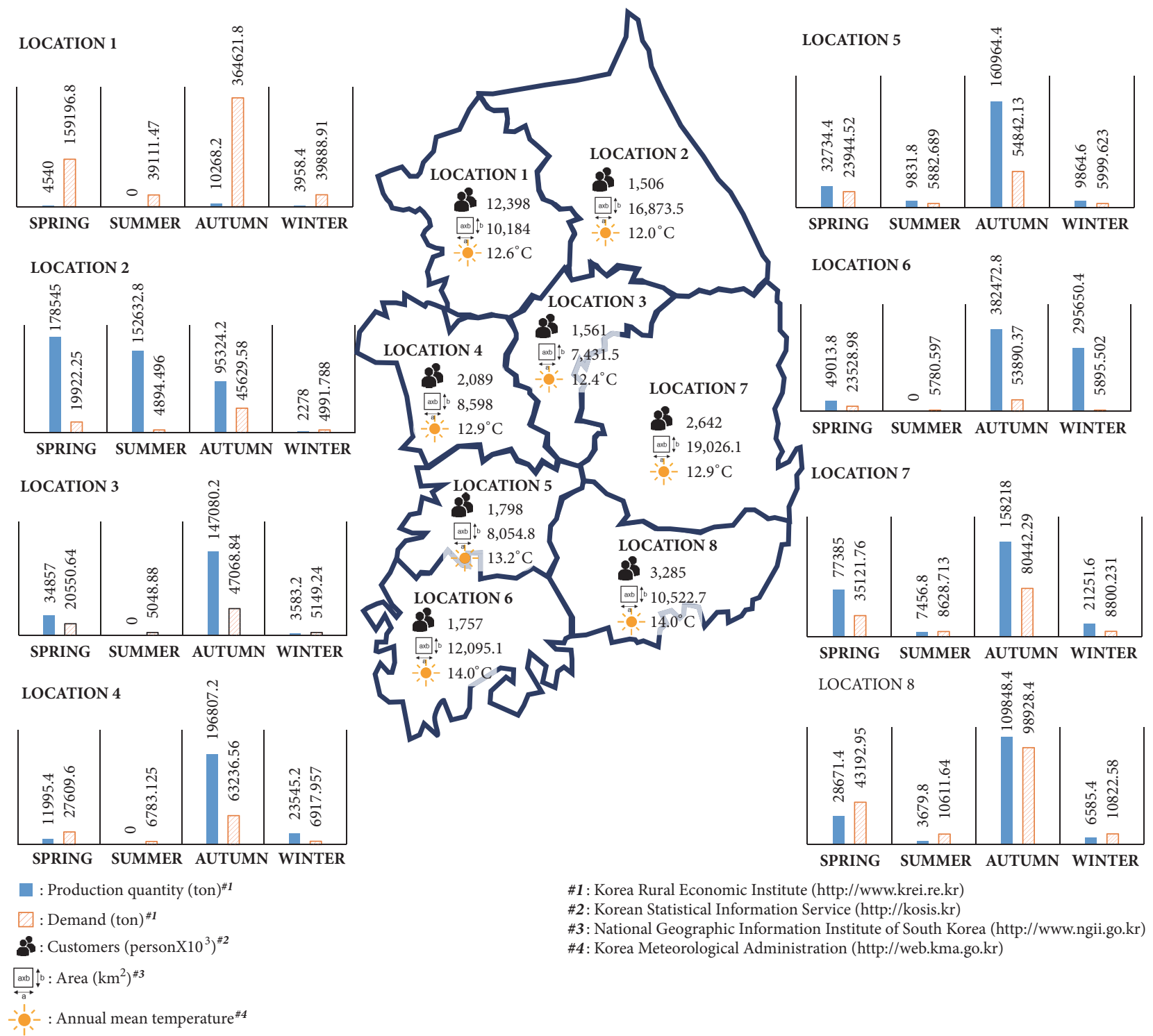

FIGURE 2: The given information of the production conditions for eight plant location candidates.

TABLE 1: Variables used in the production volume estimation.

\begin{tabular}{|c|c|c|}
\hline Variables & Description & Unit \\
\hline$P_{T}($ season $)$ & Target production volume & ton \\
\hline$P_{E}($ location, season $)$ & Estimated production volume & ton \\
\hline w_days (season) & Total number of work days & day \\
\hline$w$ hours & Maximum work hours per day & hour \\
\hline daily_util (season) & Daily utilization of a production system & $\%$ \\
\hline adj_daily_util (location, season) & Adjusted daily utilization of a production system & $\%$ \\
\hline prod_vol & Production volume per hour & ton/hour \\
\hline $\begin{array}{l}\text { total utilization of a production system } \\
\text { in the face of supply failures }\end{array}$ & 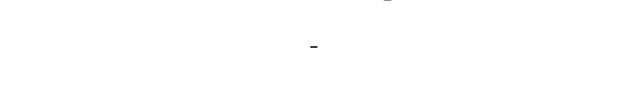 & hour \\
\hline $\begin{array}{l}\text { total utilization of a production system } \\
\text { per season }\end{array}$ & 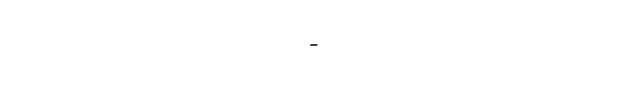 & hour \\
\hline supply_failure_time(location, season) & Total interruption time due to supply failures & hour \\
\hline
\end{tabular}


Step 1. Vulnerability analysis

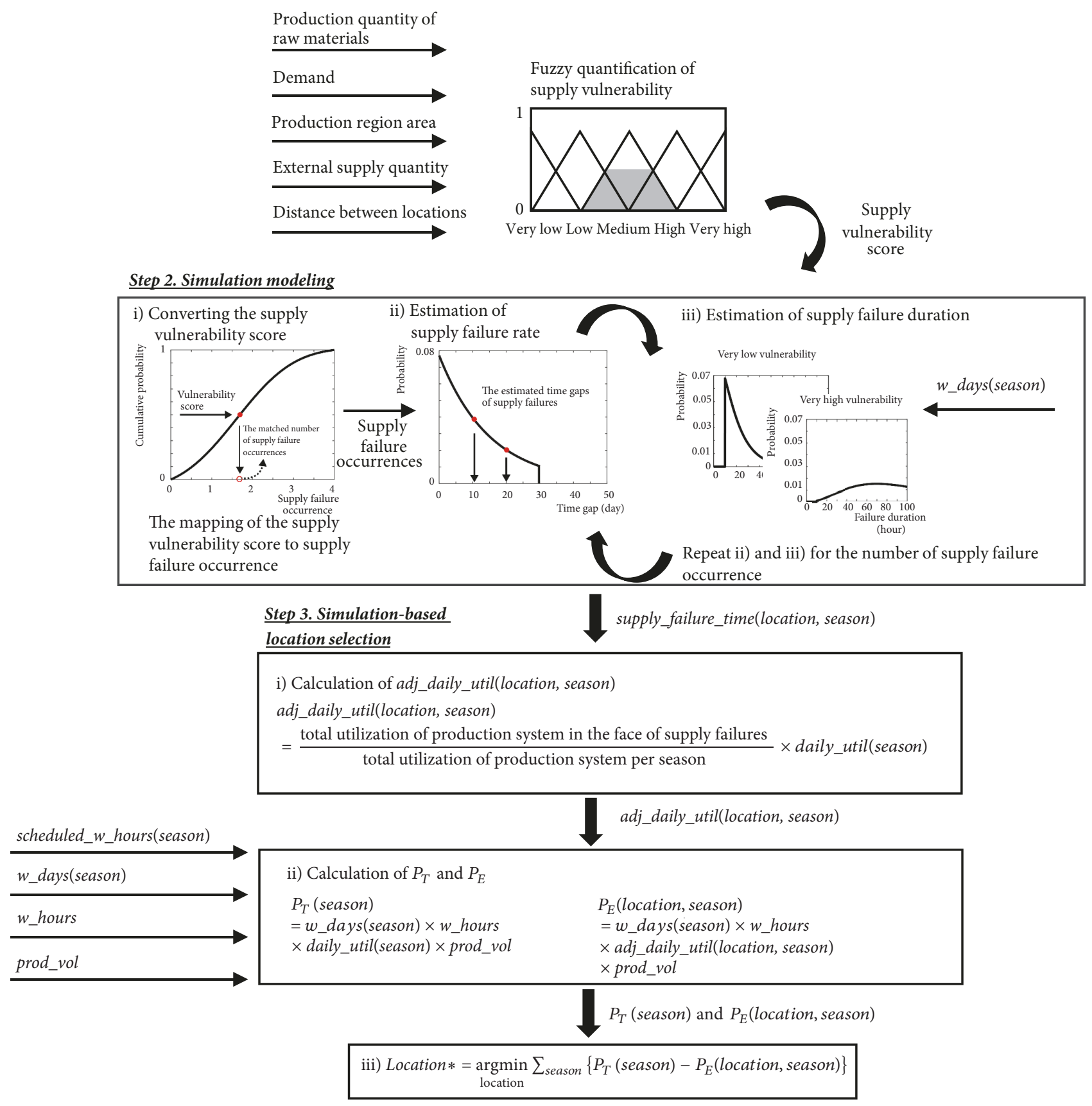

- w_days(season): the total work days during a particular season

- w_hours: the maximum work hours per day

- daily_util(season): the daily utilization of the production system with respect to daily demand and production quantities

- schedule_w_hours(season): the scheduled work hours per day for a particular season

-prod_vol: the production volume per hour (tons/hour)

FIGURE 3: The simulation-based selection procedure of a food plant location according to supply vulnerability.

linguistically assessed by considering the ratio of production quantity(location, season) to demand (location, season). production quantity(location, season) is the total amount of raw material growing in a location during a particular season, while demand(location, season) is the market demand in a location during a particular season.

(2) Production efficiency of raw materials represents the proportion of the production quantity, relative to the food-growing area in a certain location. It can be said 
TABLE 2: Fuzzy input data for the supply vulnerability of raw material.

\begin{tabular}{|c|c|c|c|c|c|c|c|c|c|c|c|}
\hline Location & Season & RA & $\mathrm{PE}$ & PR & SVL & Location & Season & RA & $\mathrm{PE}$ & PR & SVL \\
\hline \multirow{4}{*}{1} & Spring & $\mathrm{L}$ & $\mathrm{L}$ & $\mathrm{H}$ & $\mathrm{H}$ & \multirow{4}{*}{5} & Spring & $\mathrm{H}$ & $\mathrm{L}$ & $\mathrm{L}$ & $\mathrm{M}$ \\
\hline & Summer & $\mathrm{L}$ & $\mathrm{L}$ & $\mathrm{H}$ & $\mathrm{H}$ & & Summer & $\mathrm{H}$ & $\mathrm{L}$ & $\mathrm{H}$ & $\mathrm{L}$ \\
\hline & Fall & $\mathrm{L}$ & $\mathrm{H}$ & $\mathrm{H}$ & $\mathrm{L}$ & & Fall & $\mathrm{H}$ & $\mathrm{H}$ & $\mathrm{H}$ & VL \\
\hline & Winter & $\mathrm{H}$ & $\mathrm{L}$ & $\mathrm{L}$ & M & & Winter & $\mathrm{H}$ & $\mathrm{H}$ & $\mathrm{L}$ & $\mathrm{VL}$ \\
\hline \multirow{4}{*}{2} & Spring & $\mathrm{H}$ & $\mathrm{L}$ & $\mathrm{L}$ & $\mathrm{M}$ & \multirow{4}{*}{6} & Spring & $\mathrm{H}$ & $\mathrm{L}$ & $\mathrm{L}$ & $\mathrm{M}$ \\
\hline & Summer & $\mathrm{H}$ & $\mathrm{L}$ & $\mathrm{L}$ & M & & Summer & $\mathrm{L}$ & $\mathrm{L}$ & $\mathrm{L}$ & VH \\
\hline & Fall & $\mathrm{H}$ & $\mathrm{H}$ & $\mathrm{H}$ & VL & & Fall & $\mathrm{H}$ & $\mathrm{H}$ & $\mathrm{H}$ & VL \\
\hline & Winter & $\mathrm{L}$ & $\mathrm{L}$ & $\mathrm{L}$ & $\mathrm{VH}$ & & Winter & $\mathrm{H}$ & $\mathrm{H}$ & $\mathrm{L}$ & $\mathrm{VL}$ \\
\hline \multirow{4}{*}{3} & Spring & $\mathrm{H}$ & $\mathrm{L}$ & $\mathrm{L}$ & $\mathrm{M}$ & \multirow{4}{*}{7} & Spring & $\mathrm{H}$ & $\mathrm{L}$ & $\mathrm{L}$ & $\mathrm{M}$ \\
\hline & Summer & $\mathrm{L}$ & $\mathrm{L}$ & $\mathrm{H}$ & $\mathrm{H}$ & & Summer & $\mathrm{H}$ & $\mathrm{L}$ & $\mathrm{L}$ & M \\
\hline & Fall & $\mathrm{H}$ & $\mathrm{H}$ & $\mathrm{H}$ & VL & & Fall & $\mathrm{H}$ & $\mathrm{H}$ & $\mathrm{H}$ & VL \\
\hline & Winter & $\mathrm{L}$ & $\mathrm{H}$ & $\mathrm{L}$ & $\mathrm{H}$ & & Winter & $\mathrm{H}$ & $\mathrm{L}$ & $\mathrm{L}$ & M \\
\hline \multirow{4}{*}{4} & Spring & $\mathrm{L}$ & $\mathrm{L}$ & $\mathrm{L}$ & $\mathrm{VH}$ & \multirow{4}{*}{8} & Spring & $\mathrm{L}$ & $\mathrm{H}$ & $\mathrm{L}$ & $\mathrm{H}$ \\
\hline & Summer & $\mathrm{L}$ & $\mathrm{L}$ & $\mathrm{L}$ & VH & & Summer & $\mathrm{L}$ & $\mathrm{L}$ & $\mathrm{L}$ & $\mathrm{VH}$ \\
\hline & Fall & $\mathrm{H}$ & $\mathrm{H}$ & $\mathrm{H}$ & VL & & Fall & $\mathrm{H}$ & $\mathrm{H}$ & $\mathrm{H}$ & VL \\
\hline & Winter & $\mathrm{H}$ & $\mathrm{H}$ & $\mathrm{L}$ & $\mathrm{L}$ & & Winter & $\mathrm{L}$ & $\mathrm{H}$ & $\mathrm{L}$ & $\mathrm{H}$ \\
\hline
\end{tabular}

Note: RA: raw material availability; PE: production efficiency; PR: possibility of replacing raw material feedstock; SVL: supply vulnerability level; VH: very high; H: high; M: medium; L: low; VL: very low.

that the higher the production efficiency, the smaller the supply vulnerability.

(3) Possibility of replacing raw material feedstock using alternative sources represents easy accessibility of raw materials from the neighboring region, based on the fact that insufficient raw materials in a certain location can be supplemented from other locations, and it can be assessed (imprecisely) by the normalized ratio $(1 / \mathrm{n}) \sum_{\mathrm{i}=1}^{\mathrm{n}}\left(\right.$ surplus $_{\mathrm{i}} /$ distance $\left._{\mathrm{i}}\right)$. Furthermore, $\mathrm{n}$ is the number of other locations that can support the insufficient raw materials for the location being assessed, surplus $s_{i}$ is the surplus of raw materials in the $\mathrm{i}^{\text {th }}$ location, and distance $e_{\mathrm{i}}$ is the average distance between the prospective location and the $\mathrm{i}^{\text {th }}$ location that will affect delivery efficiency.

Imprecise linguistic assessments of prospective locations with respect to each factor make it difficult to do a direct quantitative evaluation of supply vulnerabilities. Fuzzy quantification is normally performed by clustering and aggregation. Experts often describe their assessment results by using linguistic descriptors such as high, medium, and small. Further, to consider the effects of unknown exogenous factors, a fuzzy aggregation method can be employed. For example, this study divided the levels of vulnerability factor values into two subgroups (i.e., low and high) using a fuzzy c-means clustering method with a conventional triangularshaped membership function [46]. We used Xie-Beni index $\mathrm{S}$, compactness and separation function, for data clustering to define a membership function, and it is efficient for easy calculation [47].

$$
S=\frac{\sum_{i=1}^{c} \sum_{k=1}^{n} u_{i, k}^{2}\left\|V_{i}-X_{k}\right\|^{2}}{n \min _{i, j}\left\|V_{i}-V_{j}\right\|^{2}},
$$

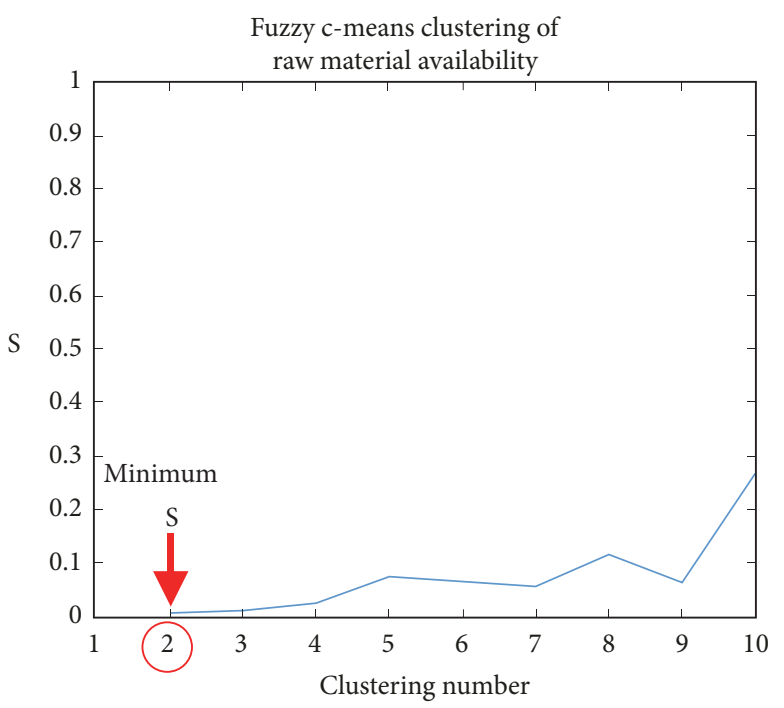

FIGURE 4: Fuzzy c-means clustering of raw material availability (S: Xie-Beni index).

where $X_{k}$ is the $k^{\text {th }}$ data point, $V_{i}$ and $V_{j}$ are cluster centroids, $u_{i, k}$ is the membership value of data $X_{k}$, and $\min _{i, j}\left\|V_{i}-V_{j}\right\|$ is the minimum distance between cluster centroids.

To find the optimal cluster number for fuzzy rules, it is necessary to find the minimum $\mathrm{S}$. Figure 4 illustrates the clustering result of raw material availability, and the clustering number 2 that minimizes $S$ will be selected as the level of vulnerability factor. Table 2 summarizes the fuzzy input data for the supply vulnerability of raw material. The conventional Mamdani method, which uses minimum implication and maximum aggregation, was employed, after which defuzzification was performed to derive an aggregated 
TABLE 3: Summary of the supply vulnerability evaluation by fuzzy quantification.

\begin{tabular}{cccccccccccc}
\hline Location & Season & RA & PE & PR & SVS & Location & Season & RA & PE & PR & SVS \\
\hline \multirow{4}{*}{1} & Spring & 7 & 4610 & 396 & 0.750 & & Spring & 146 & 5244 & 210 & 0.459 \\
& Summer & 0 & 0 & 733 & 0.750 & \multirow{2}{*}{5} & Summer & 173 & 3779 & 432 & 0.250 \\
& Fall & 54 & 10746 & 620 & 0.250 & & Fall & 302 & 10641 & 826 & 0.083 \\
& Winter & 128 & 3991 & 100 & 0.500 & & Winter & 156 & 7187 & 210 & 0.104 \\
\hline \multirow{4}{*}{2} & Spring & 939 & 4266 & 72 & 0.500 & & Spring & 184 & 4901 & 153 & 0.500 \\
& Summer & 3302 & 3448 & 12 & 0.500 & \multirow{2}{*}{6} & Summer & 0 & 0 & 184 & 0.903 \\
& Fall & 231 & 9305 & 407 & 0.110 & & Fall & 765 & 11574 & 378 & 0.113 \\
& Winter & 47 & 3831 & 80 & 0.899 & & Winter & 1455 & 6072 & 42 & 0.161 \\
\hline \multirow{4}{*}{3} & Spring & 159 & 4555 & 298 & 0.455 & & Spring & 225 & 4451 & 196 & 0.500 \\
& Summer & 0 & 0 & 374 & 0.750 & & Summer & 94 & 4041 & 293 & 0.541 \\
& Fall & 338 & 8696 & 694 & 0.093 & & Fall & 211 & 10199 & 482 & 0.103 \\
& Winter & 71 & 5423 & 137 & 0.798 & & Winter & 252 & 4381 & 89 & 0.500 \\
\hline & Spring & 41 & 4688 & 203 & 0.892 & & Spring & 68 & 5641 & 176 & 0.757 \\
4 & Summer & 0 & 0 & 297 & 0.834 & \multirow{2}{*}{8} & Summer & 30 & 3800 & 215 & 0.899 \\
& Fall & 318 & 10253 & 628 & 0.092 & & Fall & 114 & 11305 & 713 & 0.086 \\
& Winter & 368 & 5743 & 109 & 0.327 & & Winter & 57 & 5703 & 125 & 0.755 \\
\hline
\end{tabular}

Note: RA: raw material availability; PE: production efficiency; PR: possibility of replacing raw material feedstock; SVS: supply vulnerability score.

vulnerability score by means of finding the center of gravity as follows:

$$
\text { Center of gravity }=\frac{\sum_{x=a}^{b} \mu_{A}(x) x}{\sum_{x=a}^{b} \mu_{A}(x)},
$$

where $a \leq x \leq b, a, b \in \mathbf{R}, \mu_{A}(x)$ is a membership function.

The score was normalized to have a range from 0 to 1 , with 1 meaning highly vulnerable. Table 3 summarizes the supply vulnerability evaluation. Note that if food raw materials are not cultivated in a particular season and region, such that the production quantity is zero, the values of raw material availability and production efficiency of raw materials are calculated to be zero as shown in Table 3.

3.2.2. Estimation of Supply Failure Rate and Duration. This subsection describes how to derive the number of supply failure occurrences per season and the inter-supply failure time from the supply vulnerability scores. This information will provide the foundation for estimating the supply failure rate and the duration of each supply failure.

From the estimated probability distribution of failure occurrences, $f_{N}$, it is possible to identify an empirical relationship between the supply vulnerability scores and the failure occurrences. As shown in Figure 5, supply vulnerability is proportional to the cumulative probability of the supply failure occurrences. There are minimum and maximum numbers of failure occurrences during a particular season in the historical data. Thus, the random variable should be restricted for failure occurrences within a specific range. To do this, we employed truncated distribution models [48] for supply failure occurrence and duration.

The supply vulnerability score obtained in the previous subsection determined the parameters of gamma distribution (e.g., the shape parameter and the scale parameter), as shown in Figure 6. In addition, the parameters of gamma distribution were adjusted according to the failure duration information obtained by the supply vulnerability analysis. This was achieved by multiplying the average failure duration by the vulnerability score [49]. The shape parameter $\alpha$ and scale parameter $\beta$ of the truncated gamma distribution $f_{G}$ were estimated using the moments method; i.e., $\widehat{\alpha}=(\bar{\mu} / \bar{\sigma})^{2}$, $\widehat{\beta}=\bar{\sigma}^{2} / \bar{\mu}$, where $\bar{\mu}$ is the mean value of the historical data for failure durations and $\bar{\sigma}$ is its standard deviation. To include the vulnerability score in the gamma distribution, this study mapped the peak point of gamma distribution to the vulnerability score in the center of the fuzzy membership function. In this case, 0.5 was set as the reference value for which the peak point of gamma distribution correlated with supply failures, moved either to the left (more stable) or to the right (more vulnerable) (see Figure 6). The shape and scale parameters can be adjusted by modifying the mean value as follows.

$$
\begin{aligned}
\bar{\mu}^{*}= & \bar{\mu} \\
& \times(0.5+\text { Vulnerability Score (location, season }))
\end{aligned}
$$

Finally, the obtained probabilistic distribution of supply failure duration simulates the daily utilization of a food production system in a location for a particular season, i.e., adj_daily_util(location, season) (see step 3 in Figure 3).

3.3. Simulation Model of Semiprocessed Kimchi Production. Initial conditions and process information for the simulation of semiprocessed kimchi production are given in Figure 7. The target production volume of a new plant is 2,000 tons/year. The initial inter-arrival time (IAT) of raw material supply is two days. The amount of raw material per order is set as twelve tons. Eight workers handle the entire production process and they work eight hours per day. The semiprocessed kimchi production process consists 
1) The mapping process between the vulnerability score to the supply failure occurrences

(i) Generation of probability density function $f_{N}$ of truncated normal distribution from the history data of supply failure occurrences

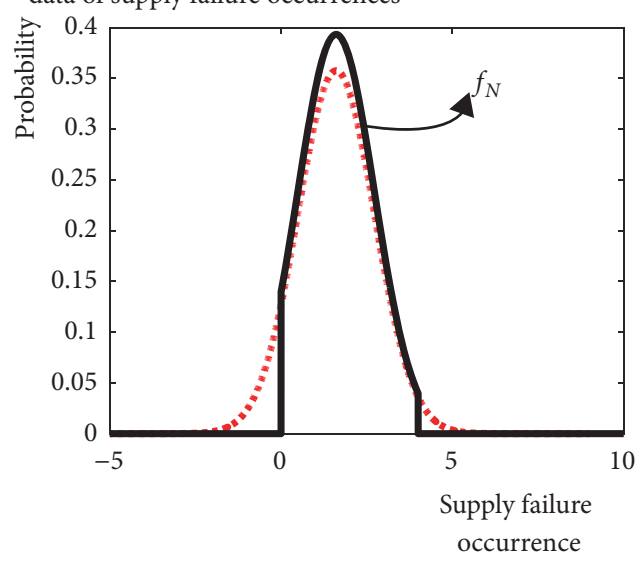

2) The estimation of supply failure rate

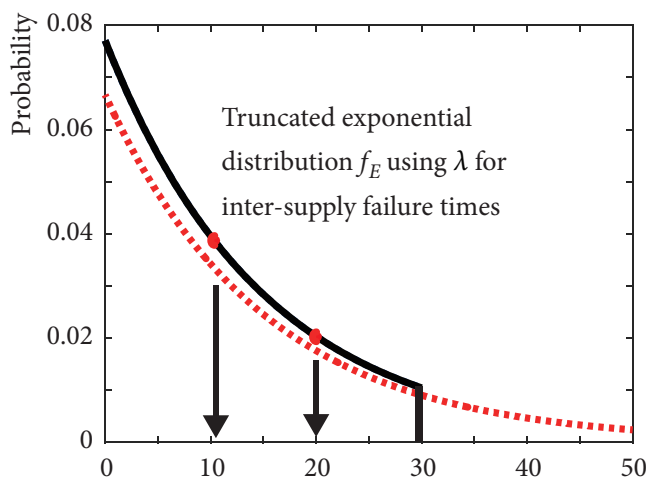

$$
\begin{array}{cccccc}
T_{n} & \cdots & T_{2} & T_{1} & \text { Inter-failure time } \\
\text { (Hour) }
\end{array}
$$

(ii) Matching the vulnerability score to the cumulative probability of $f_{N}$

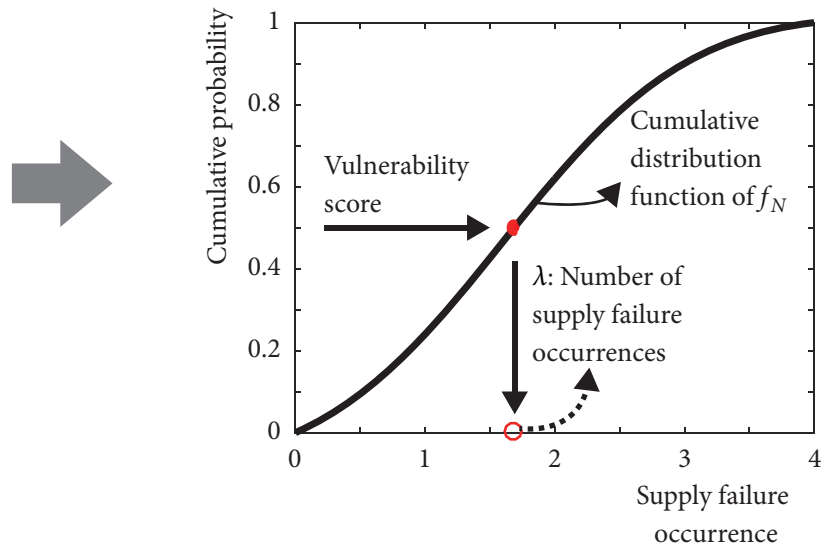

$f_{N}(x ; \bar{\mu}, \bar{\sigma}, a, b)=\frac{e^{\left(-\frac{(x-\bar{\mu})^{2}}{2 \bar{\sigma}^{2}}\right)}}{\sqrt{2 \pi} \bar{\sigma}\left\{\Phi\left[\left(\frac{b-\bar{\mu}}{\bar{\sigma}}\right)\right]-\Phi\left[\left(\frac{a-\bar{\mu}}{\bar{\sigma}}\right)\right]\right\}}$

where $\Phi$ is the cumulative distribution function $(\mathrm{CDF})$

of the probability density function (PDF) of the standard normal distribution, $a \leq x \leq b, a, b \in \mathbf{R}, \bar{\mu}$ is the mean value of historical data of supply failure occurrences, $\bar{\sigma}$ is the standard deviation of historical data

$f_{E}(x ; \lambda, b)=\lambda \frac{e^{(-\lambda x)}}{\left(1-e^{-\lambda b}\right)}$

where $\lambda$ is the number of supply failure

occurrences, $0 \leq x \leq b$

FIGURE 5: Supply failure rate estimation for stochastic simulation.

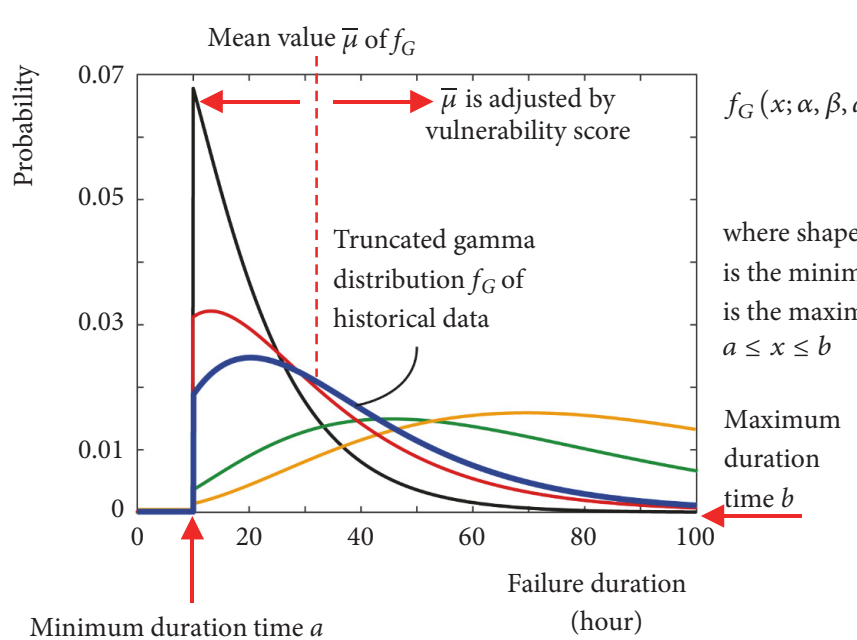

FIGURE 6: Supply failure durations in the form of gamma distributions. 
Initial conditions for simulation

- Target production volume: 2,000 tons/year

- Simulation time: 1 year

- Inter arrival time (IAT) of raw material (order): 2 days

- Amount of raw material per order: 12 tons

- Workers: 8 persons

- Working time per day: 8 hours

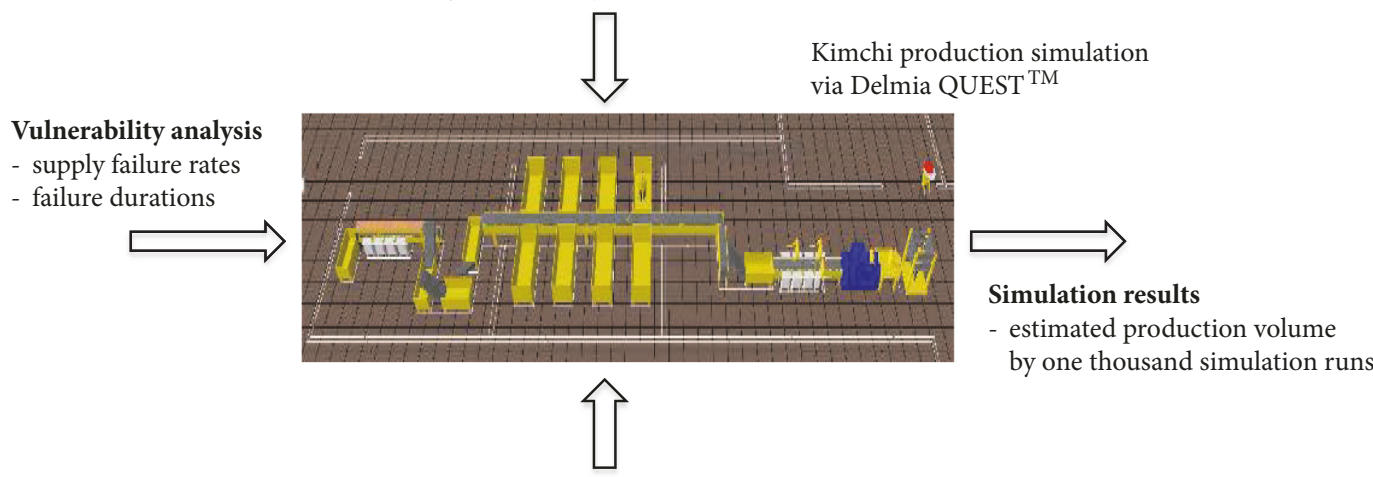

Process information for the semi-processed kimchi production

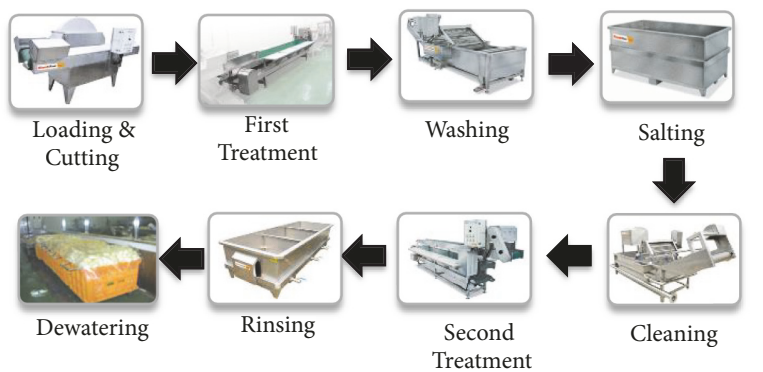

\begin{tabular}{cccc}
\hline Process & $\begin{array}{c}\text { Distribution } \\
\text { form }\end{array}$ & $\begin{array}{c}\text { Mean } \\
\text { (Shape) }\end{array}$ & $\begin{array}{c}\text { Variance } \\
\text { (Scale) }\end{array}$ \\
\hline Loading & Lognormal & $2.19977 \mathrm{~s}$ & 0.492581 \\
Cutting & Lognormal & $3.0644 \mathrm{~s}$ & 0.710918 \\
First treatment & Lognormal & $3.923 \mathrm{~s}$ & 1.67961 \\
Washing (automatic flow) & Constant & $200 \mathrm{~mm} / \mathrm{s}$ & - \\
Salting & Constant & $86400 \mathrm{~s}$ & - \\
Cleaning (automatic flow) & Constant & $200 \mathrm{~mm} / \mathrm{s}$ & - \\
Second treatment & Weibull & $21.5649 \mathrm{~s}$ & 145.318 \\
Rinsing & Lognormal & $7.91751 \mathrm{~s}$ & 9.8161 \\
Dewatering & Constant & $3600 \mathrm{~s}$ & - \\
\hline
\end{tabular}

FIGURE 7: Initial conditions and process information for the simulation of semiprocessed kimchi production.

of nine processes: loading, cutting, first treatment, washing, salting, cleaning, second treatment, rinsing, and dewatering. The operation time information of each process is given in Figure 7. The vulnerability analysis was performed to provide the supply vulnerability scores, then the supply failure rates and durations are estimated in order to adjust IAT of raw material supply during simulation.

In the simulation, raw material supply continues to produce a demand quantity. In other words, twelve tons of raw material will be supplied every two days until the simulated production volume meets the demand quantity. For this reason, there is no oversupply of raw material in the simulation. On the other hand, in case of supply failure in the simulation, the production volume cannot meet the demand quantity in the required production time, and therefore an estimated production volume is always less than a planned target production volume.

We used a commercial software, Delmia QUEST ${ }^{\mathrm{TM}}$, to simulate semiprocessed kimchi production. The QUEST model consists of six main simulation elements: part (cabbage), source (part input), sink (processed part output), machine, labor, and buffer. Refer to Figure 7 for the detailed process information. The average simulation run time for one year production without 3D animation was 39 minutes (CPU: Intel Core i7-7700 3.6GHz, RAM: 16GB).
In summary, we conducted food production simulations by considering seasonal supply variations for more detailed evaluation. However, the proposed plant location selection model aims to rank order of prospective plant locations with respect to decision attributes such as production quantity of raw materials, demand, and food-growing area in a certain location. Therefore, the rank-ordering is still possible even in the case that there is no significant difference in the seasonal supply variations.

3.4. The Best Location Selection of New Kimchi Plant. In this study, the best plant location is the one where a planned target production volume can be steadily produced, despite the unstable supply of raw materials. It is formulated as follows:

$$
\begin{aligned}
& \text { Location* } \\
& \left.=\underset{\text { location season }}{\arg \min } \sum_{T}\left\{P_{T} \text { (season }\right)-P_{E}(\text { location }, \text { season })\right\}
\end{aligned}
$$

where $P_{T}$ is the target production volume for the new plant and $P_{E}$ is the estimated production volume, considering the regional and seasonal supply vulnerability of food raw materials for the prospective location. The target production volume for a particular season, $P_{T}$ (season), is determined by:

$$
\begin{aligned}
P_{T}(\text { season })= & w \_d a y s(\text { season }) \times w \text { hours } \\
& \times \text { daily_util }(\text { season }) \times \text { prod_vol }
\end{aligned}
$$




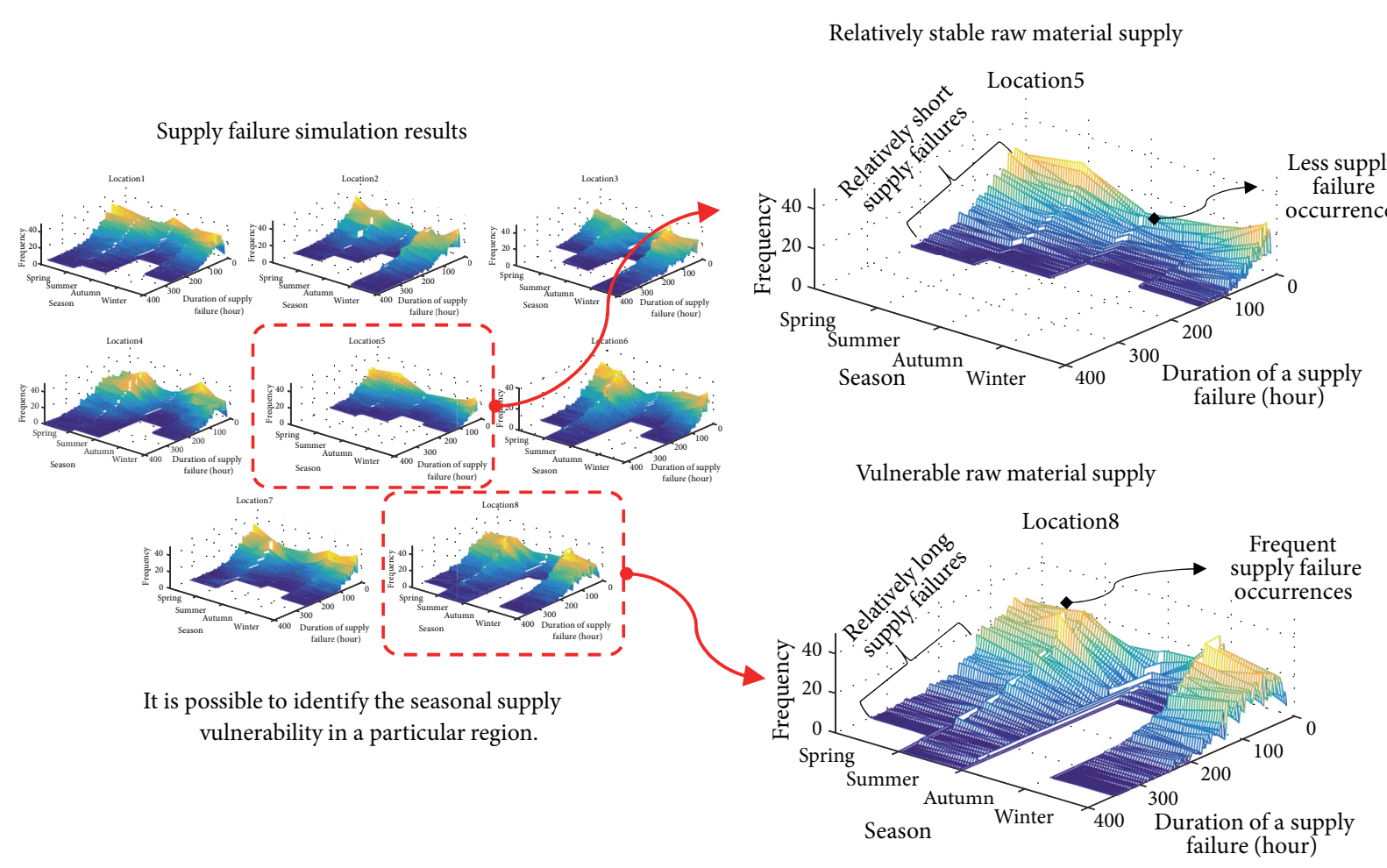

FIGURE 8: The simulation results of supply failure in locations for a year; repetition of simulation: 1,000 times; supply failure rate (occurrences/season): average 1.5, min. 0, max. 5; duration of a supply failure (day): average 2.5, min. 1, max. 20.

where $w_{-}$days (season) is the total number of work days during a particular season, $w$ _hours denotes the maximum work hours per day, and daily_util (season) indicates the daily utilization of the production system with respect to daily demand and production quantities. In addition, the daily utilization is given by the ratio of the scheduled work hours per day (scheduled_w_hours) to w_hours, and prod_vol is the production volume per hour (tons/hour). In general, daily_util (season) is assumed to be sensitive to seasonal demand to maximize the utilization of the production system.
Conversely, the estimated production volume in a location for a particular season, $P_{E}$ (location, season), is obtained by the following.

$$
\begin{aligned}
& P_{E} \text { (location, season) } \\
& =w \_ \text {days }(\text { season }) \times w \text { hours } \\
& \times \text { adj_daily_util (location, season) } \times \text { prod_vol }
\end{aligned}
$$

The adjusted daily utilization of the production system, adj_daily_util (location, season), is determined by the following simulation analysis:

$$
\begin{aligned}
\text { adj_daily_util (location, season) })= & \frac{\text { total utilization of a production system in the face of supply failures }}{\text { total utilization of a production system per season }} \\
& \times \text { daily_util(season) }
\end{aligned}
$$

where

(i) total utilization of a production system per season $=$ $w \_d a y s($ season $) \times w$ hours $\times$ daily_util(season),

(ii) total utilization of a production system in the face of supply failures $=w_{-}$days $($season $) \times w$ hours $\times$ daily_ util(season)-supply_failure_time(location, season).

The supply failure time, supply_failure_time (location, season), represents the total interruption time due to supply failures during which normal food processing is impossible for a particular season at a certain location.

3.5. Results and Discussion. Figure 8 illustrates the simulation results of supply failure durations in each prospective location for one year. There are more frequent supply failures for a relatively long duration in location 8 , particularly during spring, summer, and winter, whereas it can be said that the supply of food raw materials in location 5 is relatively 
TABLE 4: The simulated daily utilization of a new plant in each location and the gap between the target production volume and the simulated production volume.

\begin{tabular}{|c|c|c|c|c|c|c|}
\hline \multirow{2}{*}{ Location } & \multicolumn{4}{|c|}{ The Estimated Supply Failure Duration (hour) } & \multirow{2}{*}{ adj_daily_util } & \multirow{2}{*}{$\sum_{\text {season }}\left(P_{T}-P_{E}\right)$} \\
\hline & Spring & Summer & Autumn & Winter & & \\
\hline 1 & 64.55 & 66.31 & 17.43 & 36.75 & 0.895 & 1850.52 \\
\hline 2 & 38.30 & 37.71 & 8.27 & 95.93 & 0.898 & 1802.10 \\
\hline 3 & 32.27 & 60.10 & 8.18 & 70.93 & 0.903 & 1714.88 \\
\hline 4 & 91.33 & 76.53 & 7.23 & 22.67 & 0.888 & 1977.69 \\
\hline $5^{*}$ & 33.93 & 18.45 & 7.06 & 7.53 & 0.962 & 669.67 \\
\hline 6 & 36.84 & 97.52 & 8.28 & 35.10 & 0.899 & 1777.44 \\
\hline 7 & 35.80 & 41.22 & 7.40 & 37.05 & 0.931 & 1214.68 \\
\hline 8 & 67.39 & 92.49 & 7.58 & 66.84 & 0.867 & 2342.98 \\
\hline
\end{tabular}

Note: $w \_$days $($season $)=55$ days $;$ daily_util(season $)=1 ; \quad w$ hours $=8$ hours $;$ prod_vol $=10$ tonnes $/$ hour. It is assumed that $w \_$days $($season $)$and daily_util (season) of each season are the adjusted daily utilization of the production system and the target production volume in one year is 17,600 tons.

TABLE 5: An example of the supply failure occurrences in location 8 (one year simulation).

\begin{tabular}{|c|c|c|c|}
\hline Supply failure no. & Season & Delay (sec.) & Simulation clock (sec.) $\times 10^{6}$ \\
\hline 1 & Spring & 131,994 & 2.2464 \\
\hline 2 & Spring & 119,676 & 4.79759 \\
\hline 3 & Summer & 136,321 & 7.33647 \\
\hline 4 & Summer & 146,399 & 9.89199 \\
\hline 5 & Summer & 105,495 & 12.4576 \\
\hline 6 & Autumn & 87,110 & 14.9823 \\
\hline 7 & Autumn & 90,635 & 17.4886 \\
\hline 8 & Winter & 124,373 & 19.9984 \\
\hline 9 & Winter & 112,405 & 22.542 \\
\hline
\end{tabular}

stable, owing to less failure occurrences and shorter failure durations.

Table 4 summarizes the estimated supply failure duration for the four seasons, the simulation results of adj_daily_util(location, season), the estimated production volume $P_{E}$ in one year, and the gap between the target production volume $P_{T}$ and $P_{E}$ in one year. In addition, it is assumed that the total number of work days during a particular season $w_{\text {days(season) }}$ is 55 days, the maximum work hours per day $w_{\text {_hours }}$ is 8 hours, the daily utilization of the production system with respect to daily demand and production quantities daily_util(season) is full (namely, 1), the production volume per hour prod_vol is 10 tons/hour, and the target production volume in one year is 17,600 tons. The simulation results show that location 5 is the best prospective location in which the planned target production volume can be steadily achieved, despite the unstable supply of raw materials. As summarized in Table 4, the estimated supply failure duration in autumn is relatively short compared to the other seasons. This is because autumn is the harvest season, and thus raw material supply is relatively stable. Table 5 shows an example of supply failure occurrences in location 8 according to the result of one year simulation by using Delmia QUEST ${ }^{\mathrm{TM}}$, and the simulation result also shows that the supply failures in autumn are relatively shorter than the other seasons.

\section{Conclusion}

This study proposed a plant location selection procedure by simulating the daily production volume and considering the supply failures of food raw materials. This process mainly consisted of quantifying the supply vulnerability of raw materials and incorporating the quantified vulnerability scores into the stochastic simulation. We proposed the three vulnerability factors: raw material availability, production efficiency of raw materials, and possibility of replacing raw material feedstock using alternative sources, in order to quantify the regional and seasonal supply vulnerability of raw materials. These factors were then incorporated into fuzzy quantification to estimate supply vulnerability scores. The estimated supply failure information included the time gaps between failures and the duration of each failure. This information was used to determine the adjusted daily utilization and the production volume of a prospective food production plant.

The proposed simulation model will be useful for decision makers to ordinally rank plant location candidates by relative comparison of simulated production volumes. However, it is not recommended to consider the estimated production volume as a cardinal performance measure of a candidate location due to the approximated supply failure distributions with the given imprecise information. In other 
words, the proposed fuzzy vulnerability quantification and supply failure estimation methods enable simulation-based decision making even if supply failure data are not enough to estimate a probability density function using a conventional distribution fitting method.

The findings of this study can be applied and extended for two purposes: (1) to allow practitioners to effectively rank the prospective locations during the decision-making process and (2) to forecast the daily production volume of a plant in a particular location, given enough historical data, which is essential for detailed layout planning.

\section{Data Availability}

The supply failure data, food production conditions, and plant operation data used to support the findings of this study are included within the article.

\section{Conflicts of Interest}

The authors declare that they have no conflicts of interest.

\section{Acknowledgments}

This work was supported by the Korea Institute for Advancement of Technology under a research grant (no. P01070019) funded by the Ministry of Trade, Industry and Energy.

\section{References}

[1] F. ÇEbi and İ. Otay, "Multi-Criteria and Multi-Stage Facility Location Selection under Interval Type-2 Fuzzy Environment: A Case Study for a Cement Factory," International Journal of Computational Intelligence Systems, vol. 8, no. 2, pp. 330-344, 2015.

[2] Guorong Chen, Jiangyuan Zhao, and Juli Deng, "A Core Model for Parts Suppliers Selecting Method in Manufacturing Supply Chain," Mathematical Problems in Engineering, vol. 2015, Article ID 530147, 11 pages, 2015.

[3] A. Feldmann and J. Olhager, "Plant roles: Site competence bundles and their relationships with site location factors and performance," International Journal of Operations and Production Management, vol. 33, no. 6, pp. 722-744, 2013.

[4] F. V. Louveaux, "Discrete stochastic location models," Annals of Operations Research, vol. 6, no. 2, pp. 21-34, 1986.

[5] E. Pesch, F. Glover, T. Bartsch, F. Salewski, and I. Osman, "Efficient facility layout planning in a maximally planar graph model," International Journal of Production Research, vol. 37, no. 2, pp. 263-283, 1999.

[6] M. Mirhadi Fard, C. J. Kibert, and A. R. Chini, "Decisionmaking for sustainable location of a cement plant in the state of Florida," International Journal of Sustainable Engineering, vol. 9, no. 2, pp. 76-92, 2016.

[7] K.-J. Wang, B. Makond, and S.-Y. Liu, "Location and allocation decisions in a two-echelon supply chain with stochastic demand - A genetic-algorithm based solution," Expert Systems with Applications, vol. 38, no. 5, pp. 6125-6131, 2011.

[8] R. P. Manatkar, K. Karthik, S. K. Kumar, and M. K. Tiwari, "An integrated inventory optimization model for facility location-allocation problem," International Journal of Production Research, vol. 54, no. 12, pp. 3640-3658, 2016.
[9] S. H. Amin and G. Zhang, "A multi-objective facility location model for closed-loop supply chain network under uncertain demand and return," Applied Mathematical Modelling, vol. 37, no. 6, pp. 4165-4176, 2013.

[10] B. L. Shankar, S. Basavarajappa, J. C. H. Chen, and R. S. Kadadevaramath, "Location and allocation decisions for multiechelon supply chain network-a multi-objective evolutionary approach," Expert Systems with Applications, vol. 40, no. 2, pp. 551-562, 2013.

[11] X. Xu, J. Shang, H. Wang, and W.-C. Chiang, "Optimal production and inventory decisions under demand and production disruptions," International Journal of Production Research, vol. 54, no. 1, pp. 287-301, 2016.

[12] P. K. Naraharisetti and I. A. Karimi, "Supply chain redesign and new process introduction in multipurpose plants," Chemical Engineering Science, vol. 65, no. 8, pp. 2596-2607, 2010.

[13] A. B. Arabani and R. Z. Farahani, "Facility location dynamics: an overview of classifications and applications," Computers \& Industrial Engineering, vol. 62, no. 1, pp. 408-420, 2012.

[14] C. Herrera-Cáceres, F. Pérez-Galarce, E. Álvarez-Miranda, and A. Candia-Véjar, "Optimization of the harvest planning in the olive oil production: A case study in Chile," Computers and Electronics in Agriculture, vol. 141, pp. 147-159, 2017.

[15] K. L. Maass, M. S. Daskin, and S. Shen, "Mitigating hard capacity constraints with inventory in facility location modeling," Institute of Industrial Engineers (IIE). IIE Transactions, vol. 48, no. 2, pp. 120-133, 2016.

[16] B. H. Yoo and K. S. Kim, "Development of a gridded climate data tool for the COordinated Regional climate Downscaling EXperiment data," Computers and Electronics in Agriculture, vol. 133, pp. 128-140, 2017.

[17] R. Lardy, G. Bellocchi, and R. Martin, "Vuln-Indices: Software to assess vulnerability to climate change," Computers and Electronics in Agriculture, vol. 114, pp. 53-57, 2015.

[18] S. K. Deb and B. Bhattacharyya, "Fuzzy decision support system for manufacturing facilities layout planning," Decision Support Systems, vol. 40, no. 2, pp. 305-314, 2005.

[19] F. Dweiri and F. A. Meier, "Application of fuzzy decision-making in facilities layout planning," International Journal of Production Research, vol. 34, no. 11, pp. 3207-3225, 1996.

[20] S. Kumar and D. A. Nottestad, "Capacity design: An application using discrete-event simulation and designed experiments," Institute of Industrial Engineers (IIE). IIE Transactions, vol. 38, no. 9, pp. 729-736, 2006.

[21] N. Suresh Kumar and R. Sridharan, "Simulation modelling and analysis of part and tool flow control decisions in a flexible manufacturing system," Robotics and Computer-Integrated Manufacturing, vol. 25, no. 4-5, pp. 829-838, 2009.

[22] Junkang $\mathrm{He}$, Chenpeng Feng, Dan Hu, and Liang Liang, "A Decision Model for Emergency Warehouse Location Based on a Novel Stochastic MCDA Method: Evidence from China," Mathematical Problems in Engineering, vol. 2017, Article ID 7804781, 10 pages, 2017.

[23] J. Antucheviciene, Z. Kala, M. Marzouk, and E. R. Vaidogas, "Solving civil engineering problems by means of fuzzy and stochastic MCDM methods: current state and future research," Mathematical Problems in Engineering, vol. 2015, Article ID 362579, 16 pages, 2015.

[24] R. García-Flores, R. Martins, O. V. de Souza Filho et al., "A novel facility and equipment selection model for whey utilisation: A Brazilian case study," Computers and Electronics in Agriculture, vol. 117, pp. 127-140, 2015. 
[25] I. Dogan, "Analysis of facility location model using Bayesian Networks," Expert Systems with Applications, vol. 39, no. 1, pp. 1092-1104, 2012.

[26] N. Gülpınar, D. Pachamanova, and E. Çanakoğlu, "Robust strategies for facility location under uncertainty," European Journal of Operational Research, vol. 225, no. 1, pp. 21-35, 2013.

[27] M. Stephan and N. N. Wagner, "Assessing the vulnerability of supply chains using graph theory," Production Economics, vol. 126, no. 1, pp. 121-129, 2010.

[28] J. V. Vlajic, J. G. A. J. Van Der Vorst, and R. Haijema, "A framework for designing robust food supply chains," International Journal of Production Economics, vol. 137, no. 1, pp. 176-189, 2012.

[29] J. Jouzdani, S. J. Sadjadi, and M. Fathian, "Dynamic dairy facility location and supply chain planning under traffic congestion and demand uncertainty: a case study of Tehran," Applied Mathematical Modelling, vol. 37, no. 18-19, pp. 8467-8483, 2013.

[30] M. Rezaei and M. H. F. Zarandi, "Facility location via fuzzy modeling and simulation," Applied Soft Computing, vol. 11, no. 8, pp. 5330-5340, 2011.

[31] D. Ozgen and B. Gulsun, "Combining possibilistic linear programming and fuzzy AHP for solving the multi-objective capacitated multi-facility location problem," Information Sciences, vol. 268, pp. 185-201, 2014.

[32] D. Yong, "Plant location selection based on fuzzy TOPSIS," The International Journal of Advanced Manufacturing Technology, vol. 28, no. 7-8, pp. 839-844, 2006.

[33] F. Aqlan and S. S. Lam, "A fuzzy-based integrated framework for supply chain risk assessment," International Journal of Production Economics, vol. 161, pp. 54-63, 2015.

[34] R. G. Askin, I. Baffo, and M. Xia, "Multi-commodity warehouse location and distribution planning with inventory consideration," International Journal of Production Research, vol. 52, no. 7, pp. 1897-1910, 2014.

[35] A. G. Novaes, J. S. de Cursi, A. C. da Silva, and J. C. Souza, "Solving continuous location-districting problems with Voronoi diagrams," Computers \& Operations Research, vol. 36, no. 1, pp. 40-59, 2009.

[36] F. J. F. Silva and D. S. De La Figuera, "A capacitated facility location problem with constrained backlogging probabilities," International Journal of Production Research, vol. 45, no. 21, pp. 5117-5134, 2007.

[37] E. Gebennini, R. Gamberini, and R. Manzini, "An integrated production-distribution model for the dynamic location and allocation problem with safety stock optimization," International Journal of Production Economics, vol. 122, no. 1, pp. 286304, 2009.

[38] A. Diabat, K. Govindan, and V. V. Panicker, "Supply chain risk management and its mitigation in a food industry," International Journal of Production Research, vol. 50, no. 11, pp. 30393050, 2012.

[39] V. Albino and A. C. Garavelli, "A methodology for the vulnerability analysis of just-in-time production systems," International Journal of Production Economics, vol. 41, no. 1, pp. 71-80, 1995.

[40] V. Albino, A. C. Garavelli, and O. G. Okogbaa, "Vulnerability of production systems with multi-supplier network: A case study," International Journal of Production Research, vol. 36, no. 11, pp. 3055-3066, 1998.

[41] D. Petrovic, R. Roy, and R. Petrovic, "Modelling and simulation of a supply chain in an uncertain environment," European Journal of Operational Research, vol. 109, no. 2, pp. 299-309, 1998.
[42] J. G. A. J. Vorst, A. J. Beulens, W. D. Wit, and P. V. Beek, "Supply chain management in food chains: Improving performance by reducing uncertainty," International Transactions in Operational Research, vol. 5, no. 6, pp. 487-499, 1998.

[43] J. Blackburn and G. Scudder, "Supply chain strategies for perishable products: the case of fresh produce," Production Engineering Research and Development, vol. 18, no. 2, pp. 129137, 2009.

[44] S. Minegishi and D. Thiel, "System dynamics modeling and simulation of a particular food supply chain," Simulation Modelling Practice and Theory, vol. 8, no. 5, pp. 321-339, 2000.

[45] J. G. A. J. Van Der Vorst, S.-O. Tromp, and D.-J. Van Der Zee, "Simulation modelling for food supply chain redesign; Integrated decision making on product quality, sustainability and logistics," International Journal of Production Research, vol. 47, no. 23, pp. 6611-6631, 2009.

[46] M. R. Rezaee, B. P. F. Lelieveldt, and J. H. C. Reiber, "A new cluster validity index for the fuzzy C-mean," Pattern Recognition Letters, vol. 19, no. 3, pp. 237-246, 1998.

[47] X. L. Xie and G. Beni, "A validity measure for fuzzy clustering," IEEE Transactions on Pattern Analysis and Machine Intelligence, vol. 8, pp. 841-847, 1991.

[48] C. P. Robert, "Simulation of truncated normal variables," Statistics and Computing, vol. 5, no. 2, pp. 121-125, 1995.

[49] M. K. Okasha and I. M. Alqanoo, "Inference on the doubly truncated gamma distribution for lifetime data," in International Journal of Mathematics and Statistics Invention, vol. 2, pp. 1-17, 2014. 


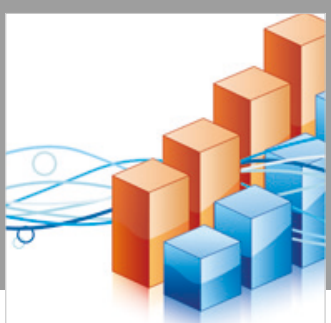

Advances in

Operations Research

\section{-n-m}
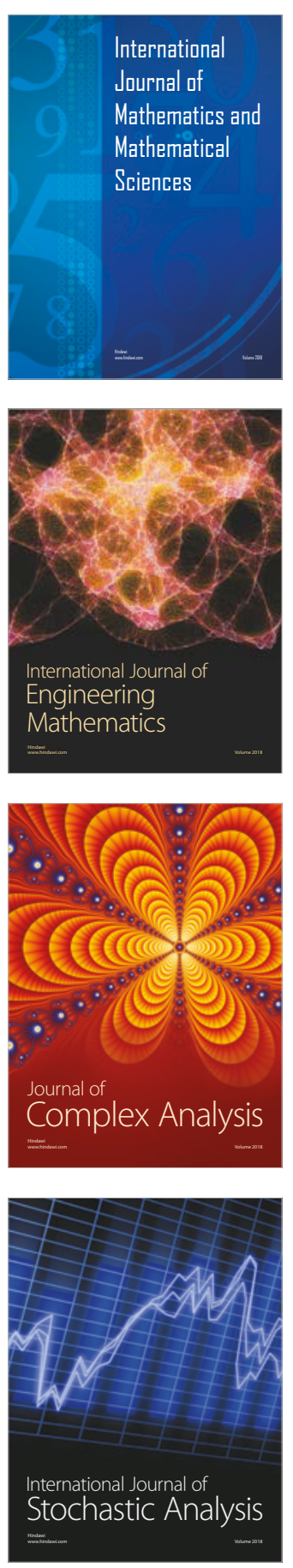
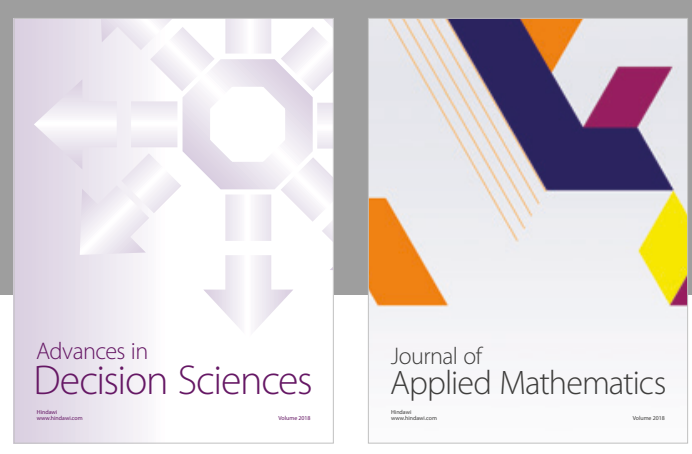

Journal of

Applied Mathematics
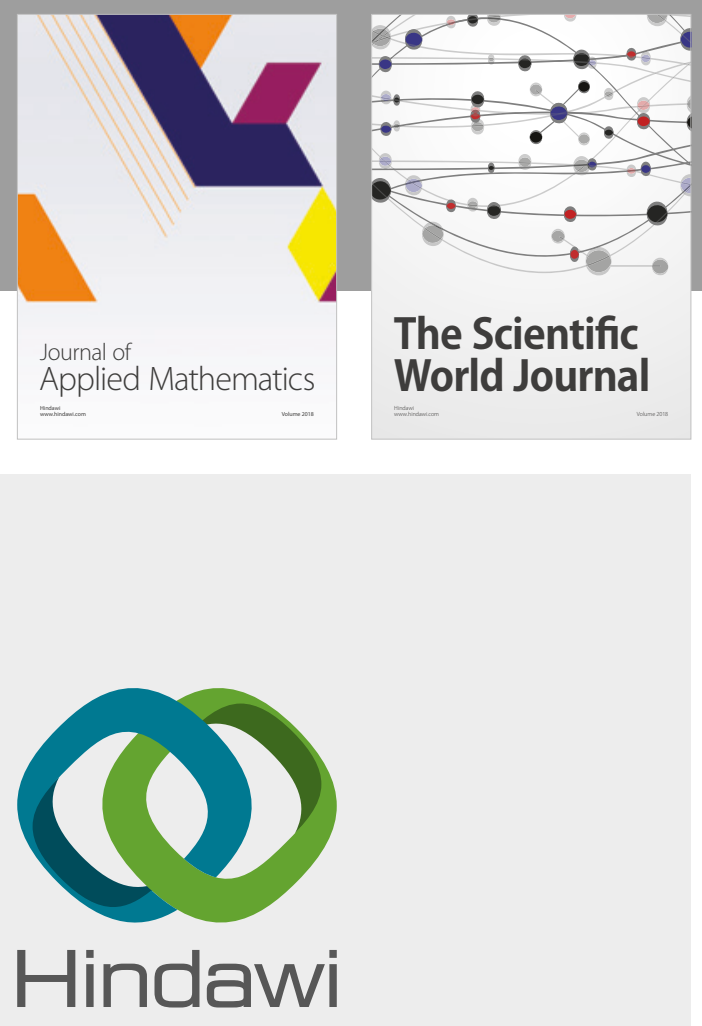

Submit your manuscripts at

www.hindawi.com

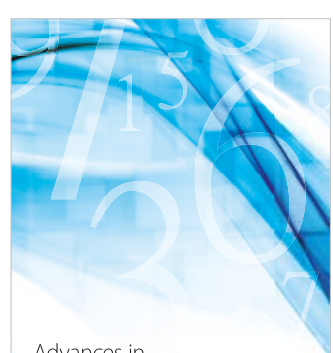

Advances in
Numerical Analysis
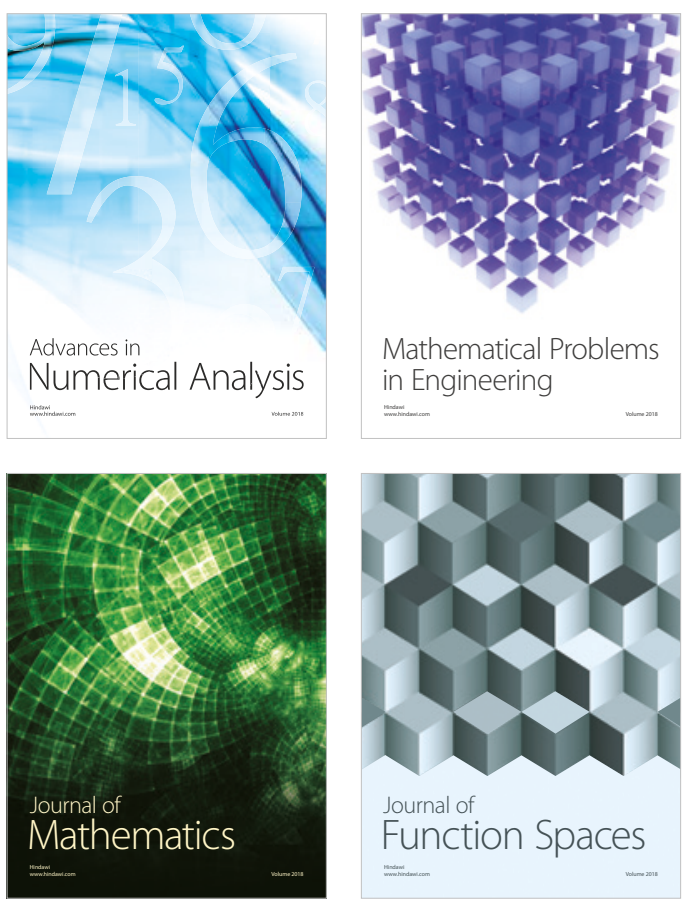

Mathematical Problems in Engineering

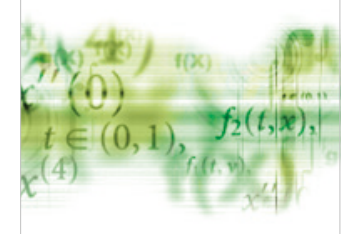

International Journal of

Differential Equations

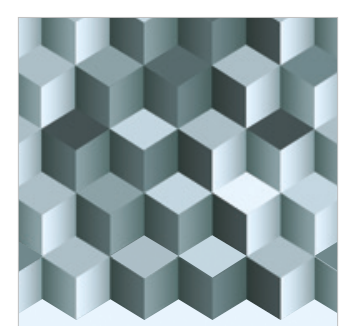

Journal of

Function Spaces

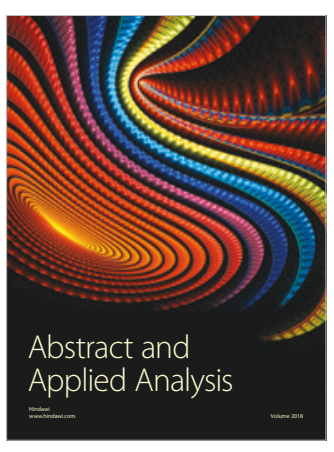

The Scientific

World Journal

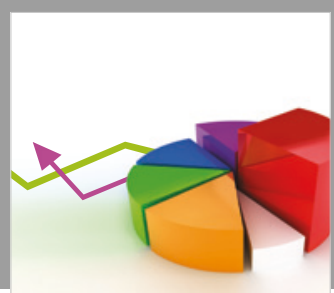

Journal of

Probability and Statistics
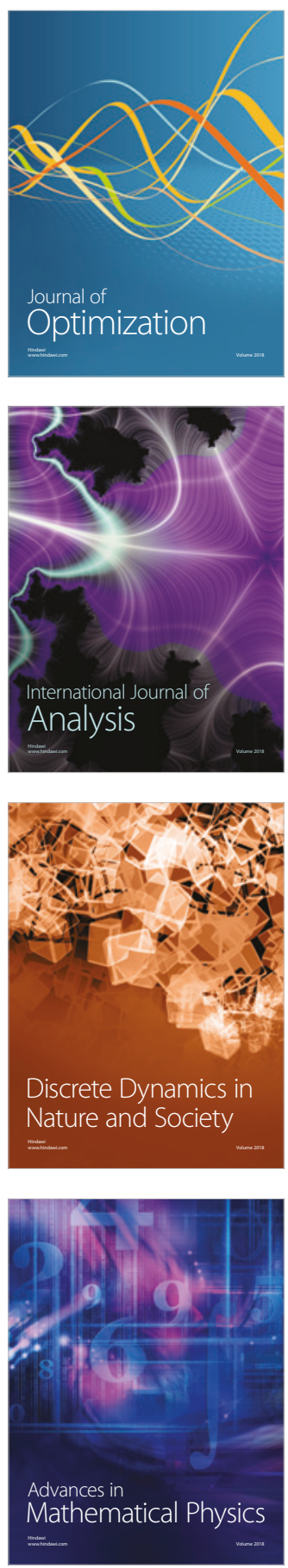